\title{
Unifocalization in Glenn shunt operation due to anatomical difficulty: A case report
}

\author{
Çağatay Bilen (D), Gökmen Akkaya (D), Osman Nuri Tuncer (D), Mehmet Fatih Ayık (D), Yüksel Atay (D \\ Department of Cardiovascular Surgery, Ege University School of Medicine, Izmir, Turkey \\ Received: May 08, 2018 Accepted: May 09, 2018 Published online: April 24, 2019
}

\begin{abstract}
Glenn shunt operation is performed to increase the pulmonary blood flow in congenital heart diseases in which ambulatory correction is unable to be performed. Pulmonary arterial flow is being balanced and thrombosis frequency is reduced via applying unifocalization of the vena cava superior in patients with bilateral vena cava superior undergoing bidirectional Glenn shunt operation. Herein, we present a case who underwent unifocal bidirectional Glenn shunt operation due to anatomical discordance.
\end{abstract}

Keywords: Glenn shunt, pulmonary artery, unifocalization.

Glenn shunt operation is a procedure used as a preoperative step prior to the Fontan procedure and is safer than single-stage Fontan procedure with lower mortality rates. ${ }^{[1,2]}$ Glenn shunt was revised in 1958 to be called bidirectional Glenn shunt and was described as an anastomosis of the pulmonary artery with vena cava superior (VCS) on the same side. ${ }^{[3]}$ Bilateral bidirectional Glenn shunt operation is applied to cases with bilateral VCS. ${ }^{[4]}$ This procedure leads to decreased shunt flow and unbalanced pulmonary blood flow, and increased frequency of stasis and thrombosis. ${ }^{[5]}$ A new step has been added to the operation of the Glenn due to these problems which is called the unifocalization of the bilateral VCS. In this report, we present a case underwent unifocal bidirectional Glenn shunt operation and the unifocalization procedure.

\section{CASE REPORT}

A four-year-old male patient on the post-natal first day echocardiogram, unbalanced atrioventricular channel, single ventricle, pulmonary atresia, and double outlet right ventricle (DORV) were detected. The patient who was assessed at the council was not found to be eligible for biventricular repair. Due to the cardiac pathologies, the patient underwent left-sided modified Blalock-Taussig (MBT) shunt operation, when he was two days old. Pulmonary artery development was found to be deficient during the postoperative catheterization. Therefore, right
MBT shunting was applied to the patient at the age of three. In further years, due to the limited pulmonary arterial development and occluded right MBT shunt which were detected during clinical follow-up via transthoracic echocardiography (TTE) and cardiac catheterization, and a new right $\mathrm{MBT}$ shunt procedure was performed for the third time at the age of seven. Routine physical examination at the time of hospital admission revealed a $2 / 6$ systolic murmur at the pulmonary valve area. Central cyanosis was also present on physical examination. Thoracic computed tomography (CT) showed malposition of the great arteries, atrial septal defect (ASD), ventricular septal defect (VSD), DORV, pulmonary stenosis, and left persistent VCS (LPVCS). The preoperative TTE results also supported the CT findings which showed a difficult access to the left pulmonary artery (Figure 1).

In the final cardiac catheterization, the McGoon index was measured as 1.8 and both left and right pulmonary arteries were measured as $12 \mathrm{~mm}$. Pulmonary artery pressures were found to be 15/9/12 mmHg. Therefore, the heart team decided to

Corresponding author: Çağatay Bilen, MD. Ege Üniversitesi Tip Fakültesi Kalp ve Damar Cerrahisi Anabilim Dalı, 35100 Bornova, İzmir, Turkey.

Tel: +90 232 - 3903571 e-mail: cagataybilen86@gmail.com

Citation:

Bilen Ç, Akkaya G, Tuncer ON, Ayık MF, Atay Y. Unifocalization in Glenn shunt operation due to anatomical difficulty: A case report. Cardiovasc Surg Int 2018;5(2):30-32. 


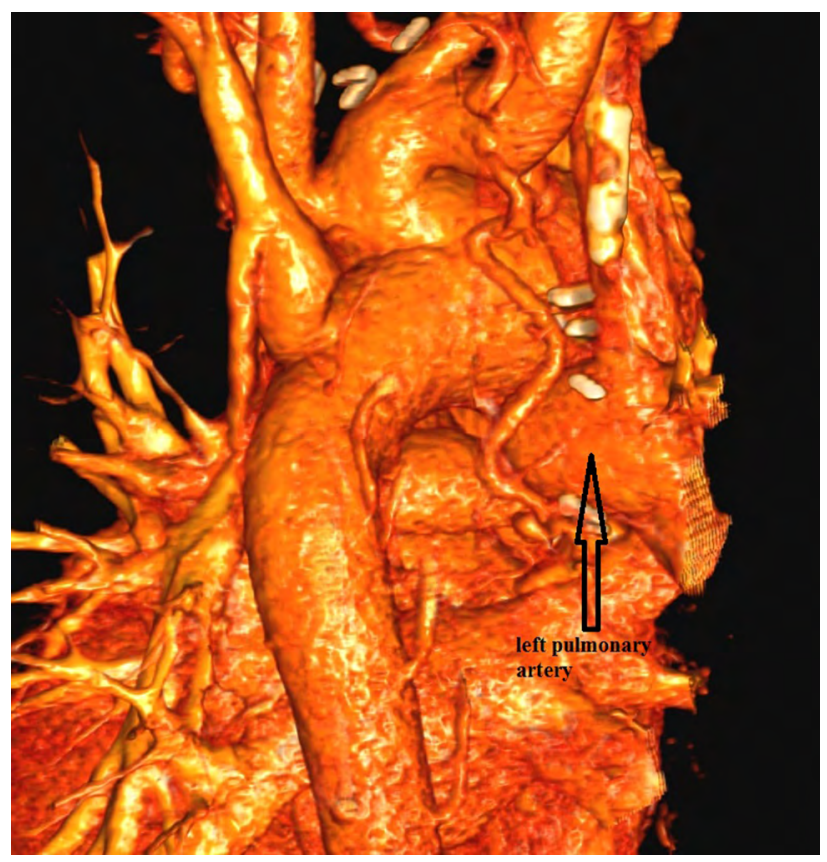

Figure 1. A computed tomography image of left pulmonary artery.

perform a Glenn shunt operation. A written informed consent was obtained from each parent.

The patient was taken to the Glenn shunt operation. Median sternotomy was performed under endotracheal general anesthesia. Adhesions were

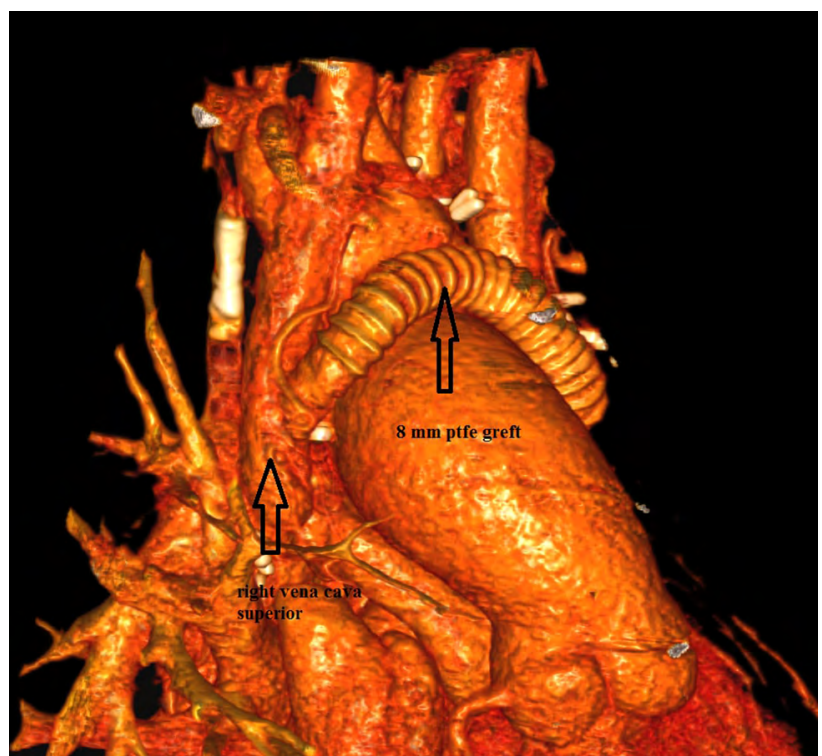

Figure 3. A postoperative three-dimensional computed tomography image of the PTFE graft between right and left superior caval veins.

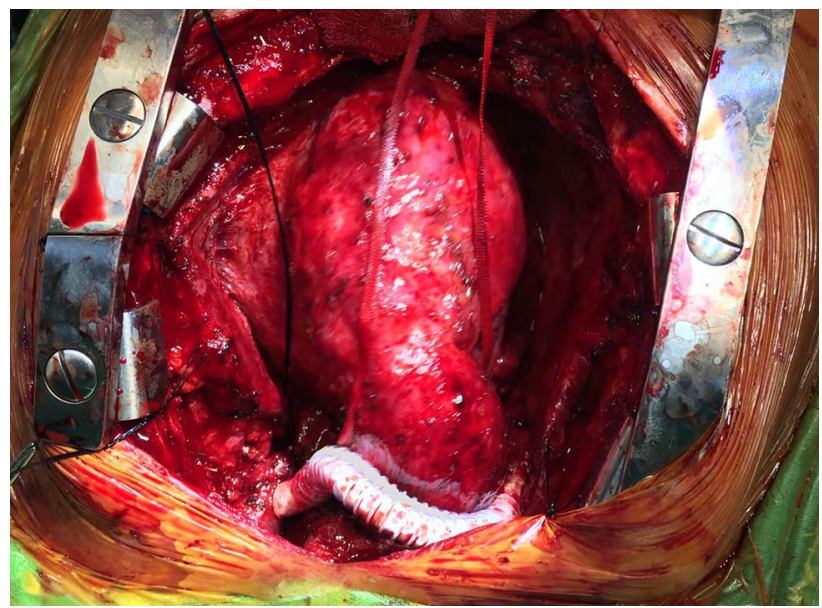

Figure 2. An introperative view of surgical field after procedure.

removed with blunt dissection. Bilateral VCS were reached and circled. The right MBT shunt was reached and turned. The left pulmonary artery was in a compelling position to be operated beneath the left atrium. First, the right VCS was amputated from where it merged with the right atrium. The amputated stump at the right atrium was, then, closed with primary sutures. The right VCS was anastomosed in an end-to-side fashion to the right pulmonary artery. The LPSVC diameter was measured as $12 \mathrm{~mm}$ in width with $22 \mathrm{mmHg}$ pressure

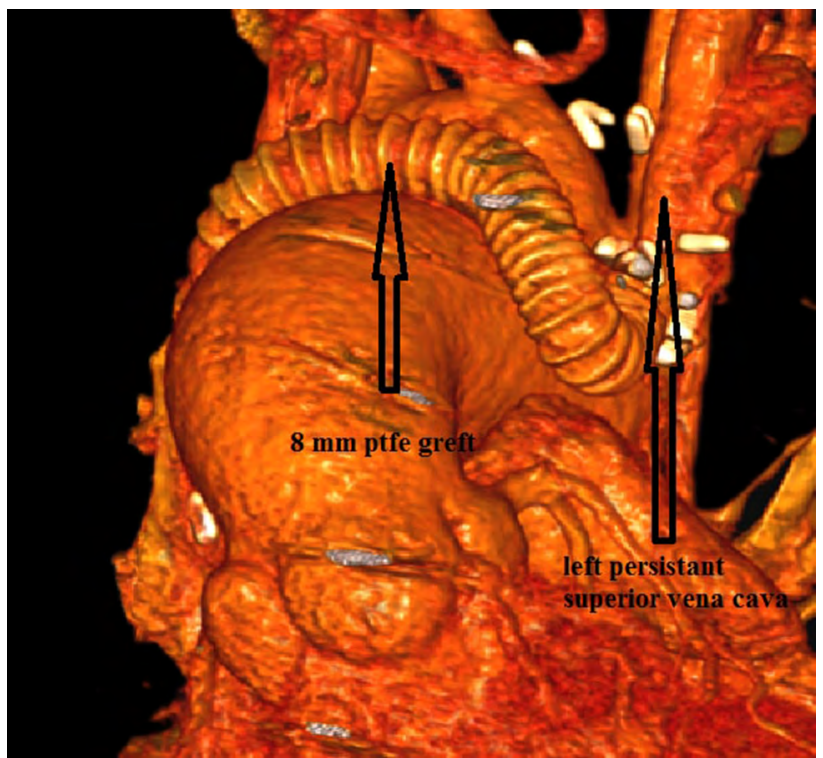

Figure 4. A postoperative three-dimensional computed tomography image of the PTFE graft between right and left superior caval veins. 
intraoperatively. Therefore, LPSVC was ligated in the distal line and planned to be anastomosed with the right VCS. Nevertheless, due to the lack of enough length, the anastomosis was able to perform via an 8-mm polytetrafluoroethylene (PTFE) ring graft. We ligated the distal part of the LPVCS and right MBT shunt. Following the bleeding control, a drain was placed in both thoraces. The operation was terminated by closing the layers appropriately to the anatomy (Figure 2).

The patient was intubated and taken to the intensive care unit. He was hemodynamically stable and did not need any inotropic support. We started antiaggregant and low-molecular-weight heparin (LMWH) treatment to the patient. He was extubated five hours after surgery. At the end of the first day, he was transferred to the ward and discharged on the postoperative eighth day. During discharge, we discontinued the LMWH treatment and continued with antiaggregant therapy. One month after the operation, control TTE showed that and the Glenn shunt was still functioning. Control CT angiography showed the 8-mm PTFE graft and patent Glenn shunt anastomosis (Figure 3, 4).

\section{DISCUSSION}

Bilateral VCS anatomy causes thrombosis due to unbalanced blood flow after Glenn shunt operation. ${ }^{[5]}$ Also, blood flow from the vena cava inferior after the Fontan procedure is not sufficient to correct the unbalanced pulmonary blood flow. This unbalanced blood flow to the pulmonary bed leads to arteriovenous malformations, which later impairs the patient comfort. ${ }^{[6]}$ Using this method, the frequency of these problems can be reduced.

The cava-pulmonary anastomosis performed during the procedure should not be small. Otherwise, edema is more common at the upper part of the body than bilaterally bidirectional Glenn shunt operation, and unequal pulmonary blood flow after bilateral bidirectional Glenn shunt operation can be seen in this method. Another important point is to ensure that the newly created innominate vein does not compress the aortic arch and its branches in the posterior. In a study of 65 patients, Kawasaki et al. ${ }^{[7]}$ observed that the perfusion of the pulmonary blood flow was balanced in the patients who underwent unifocalization procedure. In addition, Bilal et al. ${ }^{[8]}$ reported a case series including four patients in whom the LPSVC diameter was equal to the VCS and maintained the large part of systemic venous return which was threaded with a synthetic graft with an uneventful follow-up. In our case, the Glenn shunt operation with unifocalization of the VCS was performed by considering that the shunt would not run due to the large LPVCS and left anastomosis of the left atrium sizes during the operation and the other aforementioned reasons in the article.

In conclusion, unifocalization technique should be kept in mind as a feasible option, when the access of the pulmonary artery has risks and difficulties in patients undergoing the Glenn shunt operation.

\section{Declaration of conflicting interests}

The authors declared no conflicts of interest with respect to the authorship and/or publication of this article.

\section{Funding}

The authors received no financial support for the research and/or authorship of this article.

\section{REFERENCES}

1. Castaneda AR. From Glenn to Fontan. A continuing evolution. Circulation 1992;86:80-4.

2. Mayer JE Jr, Bridges ND, Lock JE, Hanley FL, Jonas RA, Castaneda AR. Factors associated with marked reduction in mortality for Fontan operations in patients with single ventricle. J Thorac Cardiovasc Surg 1992;103:444-51.

3. Glenn WW. Circulatory bypass of the right side of the heart. IV. Shunt between superior vena cava and distal right pulmonary artery; report of clinical application. N Engl J Med 1958;259:117-20.

4. Xu YQ, Liu YL, Lü XD, Li YQ, Yu CT. Bilateral bidirectional superior cavopulmonary shunt is more beneficial in medium and long term clinical outcomes than unilateral shunt. Chin Med J (Engl) 2009;122:129-35.

5. de Zélicourt DA, Pekkan K, Parks J, Kanter K, Fogel M, Yoganathan AP. Flow study of an extracardiac connection with persistent left superior vena cava. J Thorac Cardiovasc Surg 2006;131:785-91.

6. Srivastava D, Preminger T, Lock JE, Mandell V, Keane JF, Mayer JE Jr, et al. Hepatic venous blood and the development of pulmonary arteriovenous malformations in congenital heart disease. Circulation 1995;92:1217-22.

7. Kawasaki S, Nakanishi K, Takahashi H, Amano A. Evaluation of a venous unifocalization of the bilateral superior vena cava and comparison with the bilateral bidirectional glenn procedure. Juntendo Medical Journal 2016;62:141-5.

8. Bilal MS, Sarıoğlu T, Kınoğlu B, Erek E, Saltık L, Sarığlu A, et al. Konjenital kalp anomalilerine eşlik eden persistan sol superior vena kava'ya yönelik cerrahi stratejiler. Türk Kardiyol Dern Arş 1995;23:369-74. 